\title{
The Current Situation and Realization Path of Family Education: the Reference of International Policies
}

\author{
$\mathrm{Lu} \mathrm{Gao}$
}

\author{
Northeast Normal University, Chuangchun, Jilin, China, 130022 \\ *Corresponding author. Email: gaoming@cas-harbour.org
}

\begin{abstract}
With China's quality education proposal in the 21 st century, students' education has become a problem concerned by many people. Because China's current education system is mainly exam-oriented education, there is a certain degree of contradiction between literacy education requirements for children and the standards of exam-oriented education. The proposal of literacy education makes society pay more attention to family education. Therefore, many scholars and education-related government departments have studied family education, including the comparison between current family education and school education, the case study of family education consultation, the difference between Chinese and American family education, the current situation of Chinese family education, and corresponding policy suggestions. Scholars and the government have made a comprehensive and profound analysis of the problems and causes of family education, which consists of several policies and solutions but are not perfect. They blindly ask what schools and parents need to do, but do not provide parents and schools with practicable ways to implement measures. By reviewing and analyzing the current research results, this paper further explores the problems and impact of family education in China and puts forward preliminary suggestions on how to improve it. Furthermore, the research results are as follow. Firstly, it is illustrated that one of the problems of parental education is no professional guidance for parents, and the other one is communication problems between children and parents. Secondly, some suggestions stated are probably to solve these issues, which are setting courses about parental education in universities, training professional teachers to communicate with parents, and adjusting laws to restrict parents behavior.
\end{abstract}

Keyword: Competence education, family education, current situation, solutions

\section{INTRODUCTION}

From exam-oriented education to quality education, people also divide their attention to education into two main aspects, school education and family education. For example, the Department of Pedagogy in East China Normal University has compared the two types of education, including educational environment, character relations, educational methods, etc. In addition, a survey and research on adolescent family education revealed the focus and difficulties of family education in contemporary China and how to improve family education through the education consultation system. What is more, a research group of the Ministry of education on the current situation of family education suggested that family and school education should be closely combined to promote quality education. By reviewing these literature, many Chinese scholars and governments have shown their concern on family education. However, from the perspective of ordinary citizens, they realize that family education needs to be paid attention to, but specific educational methods and policies to solve the family education problems are less mentioned.

Currently, because of COVID-19 primary schools in China implemented a home online teaching mode in 2020, and "animal and beast return" became a hot word on the Internet. What is worse, during recent years, primary school students' mental health emergencies have increased significantly. Through social media, people can see many videos of parents and children quarreling over tutoring homework, which evokes the author's interest in family education and home school cooperation. Under the influence of China's exam-oriented education and college entrance 
examination system, parents have high expectations for their children, which means they pay more attention to their children's academic achievements. Therefore, family education is also a problem that parents are facing. Besides, the change of educational concept has even become the reason for declining people's fertility intention. The problem of a low neonatal birth rate is one of the leading social problems facing China. Moreover, according to the census results, even though China has launched the policy of encouraging two or even three births, the number of newborns has not increased but decreased [1]. Thus, the study of education is of great significance for the development of Chinese society. In order to further discuss family education, the paper is divided into three parts, including the introduction of the current situation and impact of family education, the analysis of the reasons for the failure of China's family education reform, and how to learn from foreign family participation policies to improve domestic family education for parents and schools.

\section{PROBLEMS AND INFLUENCE OF FAMILY EDUCATION IN CHINA}

First of all, because people consider parent education to be less important than school education, family education is becoming more and more "school-based". This means that parents regard the family as the second classroom for their children's learning and arrange many similar exercises with school for their children. There are a lot of reasons and one of these may be the influence of China's current social background, such as exam-oriented education, fierce competition in the college entrance examination, and the Confucian idea of "scholars, farmers, industry and commerce" in Chinese history, which regards scholars as the most important social class. These factors lead to parents' recognition that excellent academic achievements are very important, so that the child's family life is replaced by learning life, and parents add many extra homework and exercises to the child, but ignore the child's psychological growth and the cultivation of abilities and habits. This model of parental participation weakens the function of the family in education, and even aggravates the psychological pressure of children. For example, according to the research results of Pisa test scores, Shanghai students have excellent test scores. However, the proportion of school weariness in Shanghai is very high. This is mainly because in Shanghai, an international metropolis, parents have too much pressure on their children's learning to make their children more competitive among peer students [2]. Additionally, in China, most students' life and study are arranged by their parents, so that the children's voice is ignored, resulting in the rebellious mood of some students.
Secondly, the communication problem between parents and children also causes serious family education problems. For one thing, tiger mother has become the spokesman of some Chinese mothers, which means Chinese mothers improve their children's test scores in school through high-pressure and rigorous education [3]. For another, Chinese mothers teach their children obediently and passively. For example, they are strict in academic performance, often scold their children, and do not listen to and respect their children's opinions. Perhaps this is because Confucianism influences Chinese parents. In Confucianism, children refute their parents and challenge their parents' authority is disrespectful to their parents, which is regarded as unfilial. These views are likely to be applicable for autocratic education in ancient China, while in the context of global education, children are exposed to the integration of Eastern and Western ideas, such as the free-range education in the United States and the Western pursuit of equality, freedom, and human rights, leading to the conflict between children's thoughts and parents. Besides, nowadays, parents face fierce job competition, resulting in that they spend little time with their children. These factors lead to less and less communication between parents and children and a growing generation gap, causing the failure of family education to integrate into children's growth. However, for children, too little communication and company with their parents is a challenge to their communication skill and the ability to distinguish right from wrong, and it will have a negative impact on their world outlook and values, so that campus violence continues to occur. According to the data, the number of juvenile delinquents in China has increased tenfold in the past decade. Among them, $86.6 \%$ of the cases are because children make bad friends in their spare time, and $96 \%$ of all kinds of bad habits are formed in their spare time [4]. Therefore, companies also play an essential role in the growth and mutual understanding of their employees' children.

\section{REASONS FOR THE FAILURE OF FAMILY EDUCATION REFORM}

For family education, China once proposed parent schools in 1981, but the implementation of this policy failed. The main reason is that China separates parent education from student education. At that time, the Education Department of the Chinese government did not pay enough attention to the management and promotion of parent schools. As a result, there were no supporting policies related to parent schools to assist the advancement of parent schools, which means the government only the construct parent schools, but the education policy did not reflect the parent participation system. In addition, China has not trained professionals related to parent education and home school cooperation, resulting in the teaching content can not solve the 
problems between parents and children. Therefore, facing the severe imbalance between the development level of family education and school education in China, the concept of parental participation in other countries needs to be considered and used for reference.

\section{HOW TO IMPROVE FAMILY EDUCATION IN CHINA}

First of all, for the problem of "schooling" of family education, the main reason is that parents do not know how to cooperate with the school to improve children's learning ability through correct methods. To solve this problem, one of Ontario's policies on parental participation that establishing school committees, and cultivating and maintaining a school environment that welcomes parental participation can be learned from [5]. For example, a religious school in Canada invites parents to participate in monthly workshops for parents. At the meeting, parents discussed the topics related to family education and listened to the speeches of experts. However, many Chinese parents are occupied with working, they may not have time to participate in the regular meetings held by the school, thus China can cultivate people's attention to parent education from the time of students. For instance, policy makers can carry out family education courses in universities, so that everyone has the opportunity to have relevant basic knowledge before becoming a parent. Furthermore, when people have enough scientific awareness of children's training, Chinese schools can also establish a specific committee to ensure two-way contact and communication between parents and schools. The school committee can conduct regular online communication with parents, which provides parents with an effective way to know about their children's curriculum and performance in school and provides opportunities for parents to enter school.

In addition, another strategy of Canadian parents' participation, the new teacher induction training program (NTIP), includes resources focusing on communication between teachers and parents[5], which is also worth learning. Training professionals to have concentration on the communication between parents and schools makes up for the previous policy vacancy of parents and schools. In the changeable social environment, the educational problems of parents and schools are also fickle, so that China needs professional personnel to help parents participate.

Furthermore, to solve the communication problem between parents and children, China can learn from the laws of other countries. For example, the relevant policies of Spain require fathers to spend some time with their children every week [6]. Similarly, China can also regulate by law how much time fathers and mothers spend with their children. At the same time, the government can promulgate supporting policies, including encouraging enterprises to formulate rules to provide parents of children at a certain age with fixed time off to have time to accompany their children. Furthermore, by giving men and women a unified holiday, the state can avoid employment discrimination against women alone caused by bringing up children. Besides, U.S. law stipulates that parents may not commit acts of violence against their children, or the guardian will be fined and sentenced [7]. These detailed legal provisions impose strict restrictions on parents' behavior, which is conducive to solving the phenomenon that parents do not accompany their children due to work and other reasons. In addition, China can also learn from foreign interactive and active teaching, which states that parents and school teachers need to increase interactive learning with children and communicate between parents and children in an equal position [7]. For this concept, perhaps China can adjust the parent school to a public organization for parents and children to learn together, turning the education for parents into a platform for parents and children to learn and communicate together, which is an effective way to enhance the understanding between parents and children by coexisting as classmates, rather than according to the Confucian paternalism education, with obedience as the core.

\section{CONCLUSION}

Facing the current situation of family education in China, cooperation between parents and schools is necessary. What important is that specific measures need to be elaborated and implemented by the government departments related to education, rather than just staying in the theoretical stage. Recently, China put forward the three-child policy and promised to provide the people with corresponding supporting measures, such as parental maternity leave, protecting women's legitimate rights and interests in employment, promoting educational equity, and integrating childbearing, parenting and education. This way of making policy can also be used for reference in improving education. In globalization, the improvement of family education consciousness, the transmission of western education theory, and the modification of material conditions gradually promote and enhance family education. Therefore, the "parent school", once implemented only in some areas, can be further adjusted as a supplementary education method to help solve the existing family education problems. It is expected to the further improvement of family education and home school cooperation in China.

\section{AUTHORS' CONTRIBUTIONS}

This paper was finished by the author herself. 


\section{REFERENCES}

[1] Results of the seventh national census announced! Newborn births have dropped drastically! A record low. The results of the seventh national census announced! Newborn births have dropped drastically! A record low @ MedSci. May 11, 2021.

[2] The Ministry of Education Cares for the Next Generation Working Committee "The Characteristics, Ideas and Methods of Family Education in the New Era" Research Group. The status quo, problems and policy recommendations of family education in my country. People's Education, 2012(01): 611.

[3] Zhang, M. On "Tiger Mother Education". Educational Observation. 2019(06), 129-131.

[4] Zhao, Z. The development trend and countermeasures of family education. In: Innovation drive and the development of the capital during the "Twelfth Five-Year Plan"_An Collection of the Capital Forum 2011. 2011: 411-418.

[5] $\mathrm{Hu}, \mathrm{X}$. The impact of family policy on father participation and gender equality: A comparative study based on four European welfare systems. Journal of Shandong Women's University, 2015(05): 29-36.

[6] Zhai, C. Chinese Parents in the United States: The Conflict and Integration of Sino-American Educational Concepts. Master's thesis, Bohai University. 2016. 